\title{
Acute effects of vibration on digital circulatory function in healthy men
}

\author{
M Bovenzi, M J Griffin, C M Ruffell
}

\begin{abstract}
Objectives-To investigate the local and central pathophysiological mechanisms involved in the acute effects of unilateral vibration on the digital circulation of healthy men.
\end{abstract}

Methods-Finger blood flow (FBF) and finger skin temperature (FST) in thermoneutral conditions, and the percentage change in finger systolic pressure (FSP\%) after local cooling from 30 to $10^{\circ} \mathrm{C}$ were measured in the fingers of both hands in eight men (aged 23-47 years) who were not occupationally exposed to hand transmitted vibration. The right hand was exposed for 30 minutes to sinusoidal vibration with a frequency of $125 \mathrm{~Hz}$ and an acceleration of $87.5 \mathrm{~m} \cdot \mathrm{s}^{-2}$ rms (root mean square). A control condition consisted of exposure to static load only (10 N) without vibration. The measures of digital circulation were taken before exposure to vibration and static load and at $0,30,60$, and 90 minutes after the end of each exposure.

Results-Exposure to static load caused no significant changes in FBF, FST, or FSP\% in either the test right or the control left finger. Immediately after vibration exposure, there was a temporary increase in FBF in the vibrated right finger, whereas the non-vibrated left finger showed no vasodilation. In both the vibrated and non-vibrated fingers, FBF and FST were significantly reduced during the recovery time. A large variability between subjects was found for FBF and, to a lesser extent, for FST. In the vibrated right hand the decrease in FBF was significantly related to cold induced vasoconstriction in the digital vessels. Such a relation was not found in the nonvibrated left hand.

Conclusions-The results of this investigation suggest that acute vibration can disturb the function of digital vessels through two different and opposite mechanisms. Vibration seems to produce local vasodilation and to trigger a central sympathetic reflex vasoconstriction that can be recorded in the ipsilateral and the contralateral finger to vibration. Both local and central vasoconstrictor mechanisms are likely to be involved in the responsiveness to cold found in the digital vessels of a vibrated finger.

(Occup Environ Med 1995;52:834-841)
Keywords: acute vibration; digital vasoconstriction; pathophysiological mechanisms

Occupational exposure to vibration from hand held powered tools can give rise to a vasospastic disorder in the fingers commonly called vibration induced white finger (VWF). Nosologically, VWF is a secondary form of Raynaud's phenomenon. The finger blanching attack is caused by episodic spasm of the digital blood vessels usually triggered by cold exposure. The condition seems to be predominantly functional in character, ${ }^{1}$ even though structural changes in the vessel wall, such as medial muscular hypertrophy and perivascular fibrosis, have been reported in histological studies of the digital arteries of patients with severe VWF. ${ }^{2}$ Obstructive organic lesions in finger arteries do not seem to be present in mild and moderate cases of VWF. ${ }^{13}$ The epidemiological evidence of the reversibility of white finger symptoms after the end of vibration exposure tends to support the view that VWF is a functional disorder, at least at an early stage. ${ }^{4}$

The pathogenesis of VWF is still obscure. Central sympathetic reflex mechanisms, locally mediated mechanisms, or a combination of both have been invoked to explain the nature of the primary lesion in VWF. ${ }^{25} 6$

Among the several factors implicated in the development of VWF, the characteristics of hand transmitted vibration exposure (magnitude, frequency, direction, duration) seem to play a prominent part in the aetiology of the temporary and permanent pathophysiological changes found in the digital vessels of the exposed workers. ${ }^{7}$ Exposure to acute vibration has been used in experimental studies with both humans and animals to elucidate the mechanisms underlying the adverse effects of hand transmitted vibration on digital blood circulation. ${ }^{8-14}$ This type of study may be difficult to conduct because the physiology of digital circulation is complex and influenced by individual and environmental variables. ${ }^{1516}$ Furthermore, careful control of the experimental conditions is needed to interpret how changes in the digital haemodynamics depend on some of the characteristics of hand transmitted vibration. ${ }^{17}$

The aim of this study was to investigate the vascular response to unilateral vibration in the fingers of healthy men. A vibration frequency of $125 \mathrm{~Hz}$ was used as this frequency is representative of several occupational exposures associated with high occurrence of VWF. ${ }^{78}$ The effect of vibration on finger skin tempera- 
ture and finger blood flow in thermoneutral conditions, and on finger systolic pressure after local cooling was compared with that induced by a control condition consisting of exposure to static load without vibration. As well as the relations between finger blood flow, finger skin temperature, and finger systolic pressure, the local and central pathophysiological mechanisms involved in the acute effects of vibration on digital circulation were also investigated.

\section{Methods}

SUBJECTS

Eight male subjects, aged 23 to 47 (mean 31.4 ) years, participated in the study. Personal characteristics, general medical condition, and health of the fingers were determined for each man. All were non-smokers and none had been occupationally exposed to hand transmitted vibration. The subjects read a list of medical contraindications and gave informed written consent to the study. ${ }^{18}$ Each subject was asked not to consume coffee or alcohol for at least two hours before the tests. The volume and area of the index and ring fingers of both hands for each subject were determined by treating the cross section of each finger as an ellipse. ${ }^{19}$ The length of the finger and the depth and width of the proximal interphalangeal joint were measured with vernier callipers to an accuracy of $0.5 \mathrm{~mm}$. The volume and surface area of the finger were then calculated.

\section{ASSESSMENT OF DIGITAL CIRCULATORY FUNCTION}

Finger blood flow and finger systolic pressure were measured by strain gauge plethysmography with the Digitmatic DM2000 (Medimatic A/S, Copenhagen). Finger blood flow ( $\mathrm{ml} \cdot 100 \mathrm{ml}^{-1} \cdot \mathrm{min}^{-1}$ ) was obtained by a venous occlusion technique. A pneumatic cuff, placed around the proximal phalanx of the index finger of both hands, was instantaneously inflated to a pressure of $60 \mathrm{~mm} \mathrm{Hg}$ and volume signals were recorded with mercury in silastic strain gauges placed at the base of the finger nails. Before the venous occlusion pressure was applied, the finger was lifted and gently squeezed to allow venous outflow. For calibration, an electrical signal was used that corresponded to a voltage change of $1 \%$ that equalled a change in finger volume of $1 \%$ ( 1 $\mathrm{ml}$ blood per $100 \mathrm{ml}$ tissue). The venous occlusion plethysmographic recordings were interpreted according to the criteria of Greenfield et al. ${ }^{20}$ Three to five plethysmographic recordings of arterial inflow were made on each measurement session and the median value was taken.

Finger skin temperature $\left({ }^{\circ} \mathrm{C}\right)$ was recorded by thermocouples attached by adhesive tape to the dorsal surface of the midphalanx of the same digits in which finger blood flow was measured. The thermocouples were connected to signal conditioning and to a personal computer running data acquisition and analysis software so as to measure the temperature to an accuracy of $0.5^{\circ} \mathrm{C}$. The room temperature was measured by a free thermocouple connected to the same system.

Finger systolic pressure ( $\mathrm{mm} \mathrm{Hg}$ ) was measured during local cooling to 30 and 10 $( \pm 1)^{\circ} \mathrm{C}$ with a digit cooling system connected to the strain gauge plethysmograph. The cold test was performed by the method of Nielsen and Lassen. ${ }^{21}$ A double inlet plastic cuff $(3 \times 9$ $\mathrm{cm}$ ) for both air filling and water perfusion was placed around the midphalanx of the ring finger of both hands. An air filled cuff $(2.5 \times 9 \mathrm{~cm})$ was also applied on the proximal phalanx of the same fingers for ischaemia during cooling. The air cuff was pressurised to a suprasystolic level $(210 \mathrm{~mm} \mathrm{Hg})$ and the water cuff was perfused with water initially at $30^{\circ} \mathrm{C}$ and then at $10^{\circ} \mathrm{C}$. After five minutes of ischaemic cooling, the reopening pressure of the digital arteries was measured by strain gauge plethysmography. Systolic blood pressure in the upper arm ( $\mathrm{mm} \mathrm{Hg}$ ) was then recorded by a plethysmographic technique with a standard cuff $(12 \times 33 \mathrm{~cm})$. The percentage change of finger systolic pressure from 30 to $10^{\circ} \mathrm{C}$ (FSP\%), adjusted for changes in arm systolic pressure during the cold test, was calculated according to the following formula:

$\mathrm{FSP} \%=\left(\left(\mathrm{FSP}_{30^{\circ}}-\mathrm{FSP}_{10^{\circ}}\right) \cdot 100\right) /\left(\mathrm{FSP}_{30^{\circ}}-\left(\mathrm{ASP}_{30^{\circ}}-\mathrm{ASP}_{10^{\circ}}\right)\right)(\%)$

where $\mathrm{FSP}_{30^{\circ}}$ and $\mathrm{ASP}_{30^{\circ}}$ are the finger systolic pressure and arm systolic pressure respectively measured after five minutes ischaemia at $30^{\circ} \mathrm{C}$, and $\mathrm{FSP}_{10^{\circ}}$ and $\mathrm{ASP}_{10^{\circ}}$ are the finger systolic pressure and arm systolic pressure respectively measured after cooling to $10^{\circ} \mathrm{C}$ for five minutes. Therefore, an increase in FSP\% means cold induced digital vasoconstriction. Table 1 gives a list of the abbreviations for the measures of digital circulation cited in the text.

\section{EXPERIMENTAL PROCEDURE}

The investigation was conducted in a laboratory with mean (SD) air temperature of 24.4 $(0.7){ }^{\circ} \mathrm{C}$. Subjects wore light clothing and sat in an upright position on an adjustable chair, the hands and forearms being positioned on a table at about the level of the heart. After 20 minutes of acclimatisation, finger blood flow (FBF) was measured in the index finger of both hands. The cold test was then performed simultaneously on the ring finger of both hands followed by plethysmographic measurement of ASP. Subjects were then asked to place their right (test) hand facing downward on a wooden surface $(100 \mathrm{~mm} \times 100 \mathrm{~mm})$ attached to the table of a Derritron VP4 electrodynamic vibrator. Figure 1 shows that a Kulite force cell was located between the vibrator and the wooden surface so as to

Table 1 Measures of digital circulation performed during the investigation

\begin{tabular}{ll}
\hline FBF $=$ & finger blood flow $\left(\mathrm{ml} \cdot 100 \mathrm{ml}^{-1} \cdot \mathrm{min}^{-1}\right)$ \\
FST $=$ & finger skin temperature $\left({ }^{\circ} \mathrm{C}\right)$ \\
FSP $=$ & finger systolic pressure $(\mathrm{mm} \mathrm{Hg})$ \\
DPI & $=$ digital pressure index $(\%)$ \\
FSP $\%=$ & percentage change in finger systolic pressure after \\
& local cooling from 30 to $10^{\circ} \mathrm{C}(\%)$ \\
\hline
\end{tabular}




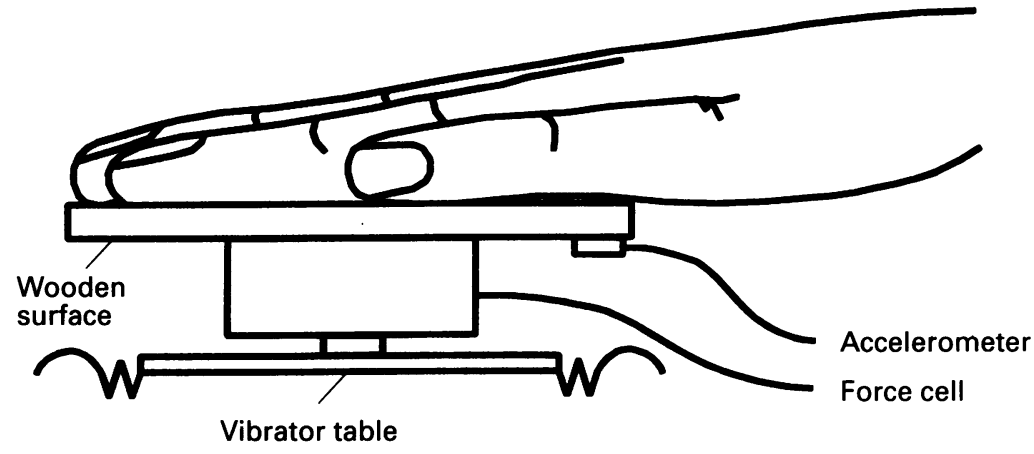

Figure 1 Arrangement for generation of vibration and control of contact force.

measure the downward force exerted by the hand. An Entran accelerometer was mounted on the underside of the wooden surface. All five fingers of the test hand were in contact with the wooden surface, but the left (control) hand was positioned palm downward on a table. Visual feedback through an analogue meter allowed a constant downward force of $10 \mathrm{~N}$ to be maintained by the right hand of the subject. Vibration was then produced in the vertical direction for 30 minutes at a frequency of $125 \mathrm{~Hz}$ and a root mean square (rms) acceleration of $87.5 \mathrm{~m} \cdot \mathrm{s}^{-2}$ (unweighted). This corresponds to a frequency weighted acceleration of $11.2 \mathrm{~m} \cdot \mathrm{s}^{-2}$ (rms) according to the International Standard ISO 5349 and the British Standard BS $6842 . .^{22} 23$ Daily exposure to this magnitude of vibration for eight years would give rise to a $10 \%$ prevalence of $\mathrm{VWF}$ according to ISO 5349 and BS 6842 . Finger blood flow was measured again immediately after vibration and at 30,60 , and 90 minutes after the end of the vibration exposure. It was not practicable to measure finger blood flow in the exposed hand during exposure to vibration because of the difficulty in obtaining plethysmographic tracings of acceptable quality. The cold test was performed at 15,30 , and $60 \mathrm{~min}$ utes after vibration. Finger skin temperature and room temperature were recorded throughout the investigation with measurements taken before provocation, every five minutes during

Table 2 Mean (SEM) values for the digital circulatory measures performed during four consecutive days in 20 healthy men at room temperature of $24^{\circ} \mathrm{C}$ (10 were tested in the vascular laboratory of Trieste (Italy), and the remaining 10 in that of Southampton (UK))

\begin{tabular}{|c|c|c|c|c|c|c|c|}
\hline \multirow[b]{2}{*}{ Variable } & \multirow[b]{2}{*}{$\begin{array}{l}\text { Time } \\
\text { (day) }\end{array}$} & \multicolumn{2}{|l|}{ Laboratory } & \multicolumn{4}{|c|}{ Repeated measures ANCOVA } \\
\hline & & $\begin{array}{l}\text { Trieste } \\
(n=10)\end{array}$ & $\begin{array}{l}\text { Southampton } \\
(n=10)\end{array}$ & Source & F ratio & $d f$ & $P$ value \\
\hline FST $\left({ }^{\circ} \mathrm{C}\right)$ & $\begin{array}{l}1 \\
2 \\
3 \\
4\end{array}$ & $\begin{array}{l}30 \cdot 0(0 \cdot 2) \\
30 \cdot 1(0 \cdot 2) \\
30 \cdot 1(0 \cdot 2) \\
30 \cdot 1(0 \cdot 2)\end{array}$ & $\begin{array}{l}30 \cdot 7(0 \cdot 2) \\
31 \cdot 0(0 \cdot 2) \\
31 \cdot 3(0 \cdot 3) \\
31 \cdot 2(0 \cdot 2)\end{array}$ & $\begin{array}{l}\mathrm{T} \\
\mathrm{L} \\
\mathrm{T} \times \mathrm{L}\end{array}$ & $\begin{array}{c}2.25 \\
20.7 \\
0.73\end{array}$ & $\begin{array}{l}3 \\
1 \\
3\end{array}$ & $\begin{array}{l}0.093 \\
0.002 \\
0.538\end{array}$ \\
\hline $\mathrm{FBF}\left(\mathrm{ml} \cdot 100 \mathrm{ml}^{-1} \cdot \mathrm{min}^{-1}\right)$ & $\begin{array}{l}1 \\
2 \\
3 \\
4\end{array}$ & $\begin{array}{l}20.9(3.1) \\
20.6(3.2) \\
20.4(2.7) \\
19.9(2.9)\end{array}$ & $\begin{array}{l}21 \cdot 7(3 \cdot 2) \\
23 \cdot 6(3 \cdot 1) \\
24 \cdot 4(2 \cdot 8) \\
25 \cdot 8(3 \cdot 6)\end{array}$ & $\begin{array}{l}\mathrm{T} \\
\mathrm{L} \times \mathrm{L}\end{array}$ & $\begin{array}{l}0.54 \\
2.76 \\
0.52\end{array}$ & $\begin{array}{l}3 \\
1 \\
3\end{array}$ & $\begin{array}{l}0.659 \\
0.114 \\
0.488\end{array}$ \\
\hline FSP (mm Hg) & $\begin{array}{l}1 \\
2 \\
3 \\
4\end{array}$ & $\begin{array}{l}110(5 \cdot 4) \\
112(4 \cdot 4) \\
106(4 \cdot 2) \\
107(5 \cdot 4)\end{array}$ & $\begin{array}{l}129(2 \cdot 9) \\
128(2 \cdot 3) \\
127(3 \cdot 3) \\
128(2 \cdot 8)\end{array}$ & $\begin{array}{l}\mathrm{T} \\
\mathrm{L} \\
\mathrm{T} \times \mathrm{L}\end{array}$ & $\begin{array}{l}0 \cdot 86 \\
6 \cdot 38 \\
0 \cdot 79\end{array}$ & $\begin{array}{l}3 \\
1 \\
3\end{array}$ & $\begin{array}{l}0.469 \\
0.022 \\
0.507\end{array}$ \\
\hline DPI (\%) & $\begin{array}{l}1 \\
2 \\
3 \\
4\end{array}$ & $\begin{array}{c}99 \cdot 3(3 \cdot 1) \\
99 \cdot 2(2 \cdot 2) \\
100(2 \cdot 0) \\
98 \cdot 9(2 \cdot 4)\end{array}$ & $\begin{array}{l}113(2 \cdot 2) \\
114(2 \cdot 5) \\
112(2 \cdot 0) \\
110(2 \cdot 3)\end{array}$ & $\begin{array}{l}\mathrm{T} \\
\mathrm{L} \\
\mathrm{T} \times \mathrm{L}\end{array}$ & $\begin{array}{c}1.12 \\
11.0 \\
0.91\end{array}$ & $\begin{array}{l}3 \\
1 \\
3\end{array}$ & $\begin{array}{l}0.349 \\
0.004 \\
0.442\end{array}$ \\
\hline
\end{tabular}

$\mathrm{P}$ values are adjusted by $\mathrm{FST}$; sources of variation: $\mathrm{T}=$ time effect; $\mathrm{L}=$ laboratory effect; $\mathrm{T} \times \mathrm{L}=$ interaction effect. provocation, and every 10 minutes during recovery. A control condition consisted of adopting the above procedure, with the vibration exposure omitted but the contact force on the wooden surface maintained. The exposed (vibration) and control (static load) conditions were presented in a balanced random order in two separated experimental sessions.

\section{REPEATABILITY OF VASCULAR MEASUREMENTS}

To assess the repeatability of the measures of digital circulation used in the current study, a preliminary investigation was conducted on 20 healthy men, aged between 21 and 37 years. Ten subjects were tested in the vascular laboratory of Trieste (Italy) and the remaining 10 in that of Southampton (United Kingdom). The same strain gauge plethysmographic apparatus and measuring techniques as for the present study were used in both laboratories. On the third left finger FBF, FSP, and FST were measured on four consecutive days, at the same time on each day. The FSP was measured without local cooling and a digital pressure index (DPI) was calculated as the ratio of finger systolic pressure to arm systolic pressure. The air temperature of the laboratories was maintained between 23 and $24^{\circ} \mathrm{C}$.

\section{STATISTICAL METHODS}

Data analysis was performed by the software BMDP/Dynamic (release $7 \cdot 0$ ). The data were summarised with the mean or median as measures of central tendency. Lower and upper quartiles, SD, or SEM were used as measures of dispersion. The coefficient of variation for the vascular measurements was estimated as the SD of the distribution expressed as a percentage of the mean. The difference between paired means was tested by the Student's $t$ test. The relation between two continuous variables was assessed by the method of the least squares. The Pearson product moment correlation coefficient was also calculated. As the present study entailed serial measurements of the same variables on the same man at several points in time, a sample size of eight men was estimated to be adequate for this type of experimental design. ${ }^{24}$ Repeated measures analysis of variance (ANOVA) was used to test the hypothesis of no difference in the vascular responses under different exposure conditions. To adjust for the influence of individual and environmental variables, repeated measures analysis of covariance (ANCOVA) was also used. The assumption of symmetry for the orthogonal polynomial components of repeated measures was checked by a sphericity test found in Anderson..$^{25}$ When the symmetry assumption was violated, a conservative test of the repeated measures factor was used by reducing the degrees of freedom of the $F$ ratio (Greenhouse-Geisser method). ${ }^{26}$ A P value of 0.05 (two sided) was chosen as the limit of significance.

\section{Results}

REPEATABILITY OF VASCULAR MEASUREMENTS Table 2 shows the means (SEMs) for the 
Figure 2 Regression of finger blood flow (FBF) in the test finger at room temperature before and after 30 minutes exposure to vibration: $F B F=-105.9$ $+4.95(R T) ; r=0.51$ $(P<0.001)$.

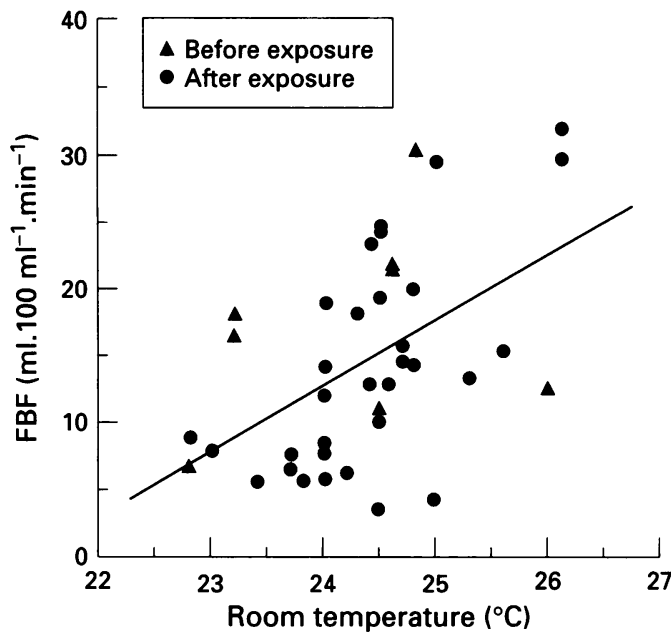

preliminary measures of digital circulation in four different testing sessions. The coefficients of variation across trials for 20 men averaged $21.4 \%$ for FBF, $4.7 \%$ for FSP, and $3.4 \%$ for DPI. ANCOVA for repeated measures showed no significant difference between the four sessions for all of the digital circulatory measures. Pressure indices and FST differed between laboratories, but the interaction with testing sessions was not significant, indicating that the profiles for the two laboratories had similar shapes. Taking into account that subsequent experiments took place in one of the laboratories, the repeatability of vascular measurements was considered to be acceptable.

INDIVIDUAL AND ENVIRONMENTAL FACTORS In the present study, with exposure to either static load or vibration, FBF was found to be positively correlated with finger volume $(0.001<\mathrm{P}<0.04)$ and room temperature $(0.001<\mathrm{P}<0.02)$, while an inverse correlation with age was found $(0.001<\mathrm{P}<0.02)$. As an example, figure 2 shows the estimated regression line and the scattergram for pairs of room temperature and FBF measured in the test finger before and after 30 minutes exposure to vibration. The patterns of the relation of FST with age and room temperature were similar to those found for FBF. Cold induced increase in FSP\% (digital arterial vasoconstriction) was inversely correlated with room temperature $(P<0.01)$, whereas finger systolic pressure and arm systolic pressure after cooling to 30 and $10^{\circ} \mathrm{C}$ tended to increase with increasing age $(0.001<\mathrm{P}<0.02)$. These results suggest that haemodynamics in the digital vessels was significantly related to individual characteristics and environmental conditions. Therefore, in the analysis of variance for repeated measures of digital circulation, age and finger volume or area were used as constant covariates, whereas room temperature was used as a covariate that changed across trials. There was no difference in the mean (SD) values of air temperature measured in the laboratory during exposure to static load $\left(24.4(0.7)^{\circ} \mathrm{C}\right)$ and vibration $(24.5$ $\left.(0 \cdot 7)^{\circ} \mathrm{C}, \mathrm{P}>0 \cdot 1\right)$.

\section{STATIC LOAD}

Exposure to static load for 30 minutes caused no significant change in FBF (table 3), FST (table 4), or FSP\% (table 5) in either the test right hand or the control left hand. A large within and between subject variability was found for blood flow measured in both fingers. Even though FBF and FST tended to fall after exposure, ANCOVA did not show any

Table 3 Median values and lower and upper quartiles (LQ-UQ) for finger blood flow $\left(\mathrm{ml} \cdot 100 \mathrm{ml}^{-1} \cdot \mathrm{min}^{-1}\right)$ measured in eight healthy men before and after 30 minutes exposure to static load (contact force $10 \mathrm{~N}$ ) and vibration (acceleration $87 \cdot 5 \mathrm{~ms}^{-2} \mathrm{rms}_{\text {at }} 125 \mathrm{~Hz}$ )

\begin{tabular}{|c|c|c|c|c|c|c|c|c|}
\hline \multirow[b]{3}{*}{ Period } & \multicolumn{4}{|l|}{ Static load } & \multicolumn{4}{|l|}{ Vibration exposure } \\
\hline & \multicolumn{2}{|l|}{ Exposed finger } & \multicolumn{2}{|l|}{ Non-exposed finger } & \multicolumn{2}{|l|}{ Exposed finger } & \multicolumn{2}{|l|}{ Non-exposed finger } \\
\hline & Median (LQ-UQ) & $(\%)$ & Median (LQ-UQ) & $(\%)$ & Median (LQ-UQ) & $(\%)$ & Median (LQ-UQ) & $(\%)$ \\
\hline $\begin{array}{l}\text { Before exposure } \\
\text { Recovery (min): }\end{array}$ & $17 \cdot 9(6 \cdot 6-29 \cdot 1)$ & $(100)$ & $16.9(8 \cdot 5-19 \cdot 6)$ & $(100)$ & $17 \cdot 2(10 \cdot 7-21 \cdot 8)$ & $(100)$ & $13 \cdot 2(11 \cdot 3-26 \cdot 0)$ & $(100)$ \\
\hline $\begin{array}{l}\text { R } 0 \\
\text { R } 30 \\
\text { R } 60 \\
\text { R } 90\end{array}$ & $\begin{array}{l}17 \cdot 0(8 \cdot 8-40 \cdot 4) \\
16 \cdot 0(6 \cdot 2-24 \cdot 3) \\
15 \cdot 9(8 \cdot 1-24 \cdot 7) \\
10 \cdot 1(6 \cdot 1-22 \cdot 8)\end{array}$ & $\begin{array}{l}(97 \cdot 4) \\
(101) \\
(92 \cdot 0) \\
(83 \cdot 2)\end{array}$ & $\begin{array}{l}16 \cdot 1(9 \cdot 1-17 \cdot 9) \\
12 \cdot 9(6 \cdot 7-25 \cdot 7) \\
14 \cdot 1(8 \cdot 4-18 \cdot 7) \\
10 \cdot 4(5 \cdot 8-17 \cdot 4)\end{array}$ & $\begin{array}{l}(95 \cdot 6) \\
(102) \\
(94 \cdot 6) \\
(74 \cdot 4)\end{array}$ & $\begin{array}{c}19 \cdot 6(10 \cdot 3-28 \cdot 5) \\
18 \cdot 5(7 \cdot 8-24 \cdot 1) \\
10 \cdot 2(6 \cdot 8-14 \cdot 8) \\
9 \cdot 4(5 \cdot 8-13 \cdot 9)\end{array}$ & $\begin{array}{l}(117) \\
(102) \\
(65 \cdot 2) \\
(55 \cdot 7)\end{array}$ & $\begin{array}{c}13 \cdot 9(11 \cdot 1-23 \cdot 2) \\
14 \cdot 6(9 \cdot 4-19 \cdot 8) \\
8 \cdot 4(4 \cdot 2-16 \cdot 1) \\
7 \cdot 3(3 \cdot 4-14 \cdot 7)\end{array}$ & $\begin{array}{l}(102) \\
(85 \cdot 5) \\
(60 \cdot 9) \\
(47 \cdot 7)\end{array}$ \\
\hline $\begin{array}{l}\text { ANCOVA } \\
\text { ( } \mathrm{P} \text { value) }\end{array}$ & 0.226 & 0.333 & $0 \cdot 130$ & 0.644 & 0.002 & 0.003 & $<0.001$ & $<0.001$ \\
\hline
\end{tabular}

$\mathrm{P}$ values are adjusted by age, finger volume, and room temperature; $(\%)=$ percentage of value before exposure.

Table 4 Median values and lower and upper quartiles (LQ-UQ) for finger skin temperature $\left({ }^{\circ} \mathrm{C}\right)$ measured in eight healthy men before and after 30 minutes of exposure to static load (contact force $10 \mathrm{~N}$ ) and vibration (acceleration $87.5 \mathrm{~ms}^{-2} \mathrm{rms}$ at $125 \mathrm{~Hz}$ )

\begin{tabular}{|c|c|c|c|c|c|c|c|c|}
\hline \multirow[b]{3}{*}{ Period } & \multicolumn{4}{|l|}{ Static load } & \multicolumn{4}{|l|}{ Vibration exposure } \\
\hline & \multicolumn{2}{|l|}{ Exposed finger } & \multicolumn{2}{|l|}{ Non-exposed finger } & \multicolumn{2}{|l|}{ Exposed finger } & \multicolumn{2}{|l|}{ Non-exposed finger } \\
\hline & Median (LQ-UQ) & $(\%)$ & Median (LQ-UQ) & $(\%)$ & Median (LQ-UQ) & $(\%)$ & Median (LQ-UQ) & $(\%)$ \\
\hline $\begin{array}{l}\text { Before exposure } \\
\text { Recovery (min): }\end{array}$ & $32 \cdot 2(31 \cdot 3-33 \cdot 8)$ & $(100)$ & $33 \cdot 3(32 \cdot 1-35 \cdot 2)$ & $(100)$ & $32 \cdot 3(30 \cdot 1-34 \cdot 4)$ & $(100)$ & $33 \cdot 5(31 \cdot 1-36 \cdot 0)$ & $(100)$ \\
\hline $\begin{array}{l}\text { R } 0 \\
\text { R } 30 \\
\text { R } 60 \\
\text { R } 90\end{array}$ & $\begin{array}{l}33 \cdot 1(31 \cdot 3-34 \cdot 6) \\
33 \cdot 2(29 \cdot 1-34 \cdot 3) \\
31 \cdot 5(30 \cdot 3-33 \cdot 4) \\
30 \cdot 1(29 \cdot 3-33 \cdot 5)\end{array}$ & $\begin{array}{l}(103) \\
(103) \\
(98 \cdot 2) \\
(94 \cdot 1)\end{array}$ & $\begin{array}{l}34 \cdot 6(32 \cdot 6-35 \cdot 9) \\
34 \cdot 2(29 \cdot 6-36 \cdot 0) \\
32 \cdot 7(29 \cdot 9-34 \cdot 8) \\
31 \cdot 7(28 \cdot 7-34 \cdot 8)\end{array}$ & $\begin{array}{l}(102) \\
(101) \\
(98 \cdot 5) \\
(96 \cdot 2)\end{array}$ & $\begin{array}{l}34 \cdot 3(31 \cdot 8-35 \cdot 3) \\
33 \cdot 1(30 \cdot 7-34 \cdot 6) \\
30 \cdot 8(29 \cdot 0-34 \cdot 1) \\
29 \cdot 6(27 \cdot 9-33 \cdot 6)\end{array}$ & $\begin{array}{l}(106) \\
(97 \cdot 2) \\
(89 \cdot 9) \\
(86 \cdot 5)\end{array}$ & $\begin{array}{l}34 \cdot 7(33 \cdot 6-36 \cdot 3) \\
34 \cdot 2(32 \cdot 0-35 \cdot 4) \\
31 \cdot 5(28 \cdot 9-35 \cdot 3) \\
30 \cdot 1(28 \cdot 4-34 \cdot 8)\end{array}$ & $\begin{array}{l}(101) \\
(97 \cdot 4) \\
(89 \cdot 2) \\
(86 \cdot 6)\end{array}$ \\
\hline $\begin{array}{l}\text { ANCOVA } \\
\text { (P value) }\end{array}$ & $0 \cdot 103$ & $0 \cdot 246$ & $0 \cdot 120$ & $0 \cdot 350$ & 0.022 & 0.031 & 0.004 & 0.008 \\
\hline
\end{tabular}

$P$ values are adjusted by age, finger area, and room temperature; $(\%)=$ percentage of value before exposure. 
Figure 3 Regression between the change in finger blood flow (FBF) at 90 minutes after vibration ended and FBF

immediately after vibration recorded in both the test

and the control fingers. The change in $F B F(y)=((C-$ $B) / A) \times 100$, where $A=$ $F B F$ before vibration, $B=$ $F B F$ immediately after vibration, $C=F B F$ after 90 minutes. The percentage FBF immediately after vibration $(x)=$ $(B / A) \times 100$. The regression line was estimated excluding the outlier denoted with an open circle: $y=82 \cdot 7-1 \cdot 32$ $(x) ; r=-0.84$ (outlier excluded, $P<0.001)$ $r=-0.72$ (all data $P=0.002$ ).

Figure 4 Regression of finger skin temperature (FST) on finger blood flow (FBF) measured in the test finger before 30 minutes exposure to vibration and during 90 minutes recovery: $F S T=22 \cdot 9+3 \cdot 60$ $(\ln (F B F)) ; r=0.74$ $(P<0.001)$.
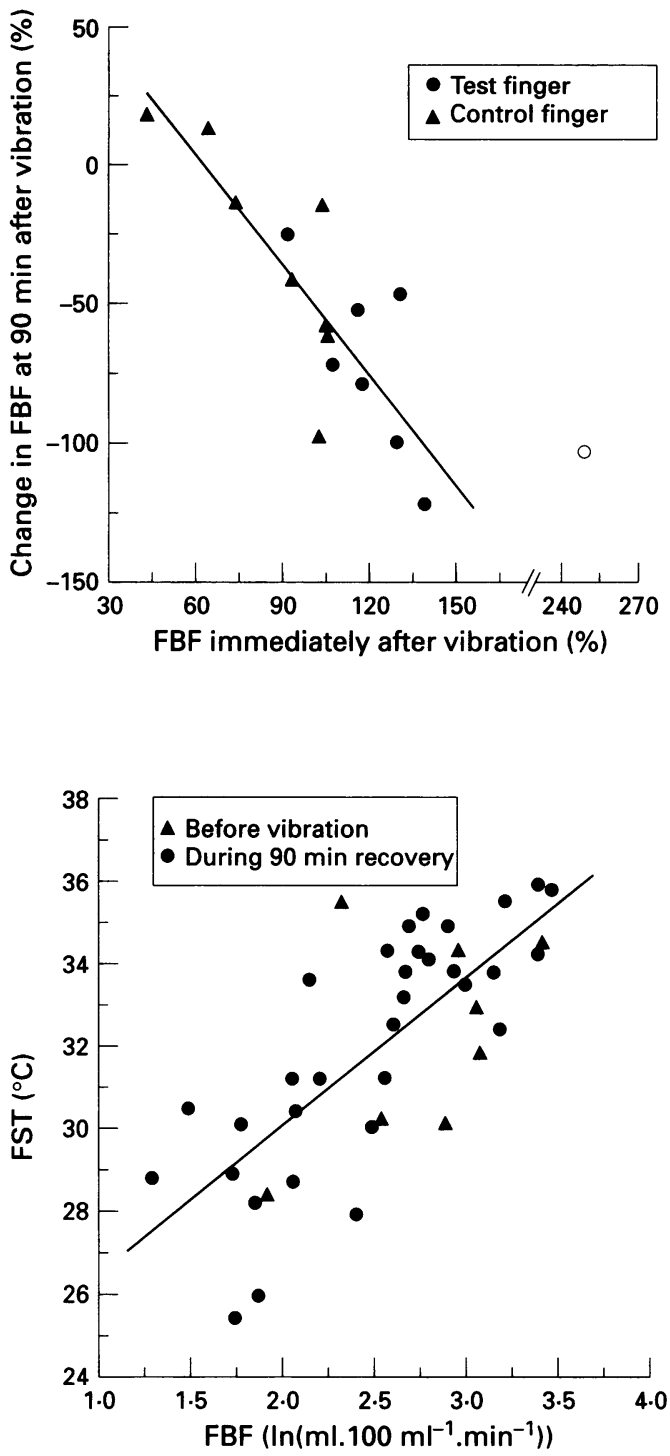

significant difference between repeated measurements performed before exposure and during the recovery time. FBF was significantly correlated with FST $(P<0.001)$, but not with cold induced changes in FSP\% $(\mathrm{P}>0 \cdot 1)$.

\section{VIBRATION}

Hand transmitted vibration induced a temporary increase in FBF in the vibrated right finger $(17 \%, P<0.05)$ immediately after the end of exposure (table 3 ). Then blood flow significantly fell during the recovery time $(P=$ $0.002)$. The non-vibrated left finger showed no vasodilatation when vibration stopped and blood flow fell roughly at a rate of $15 \%$ for

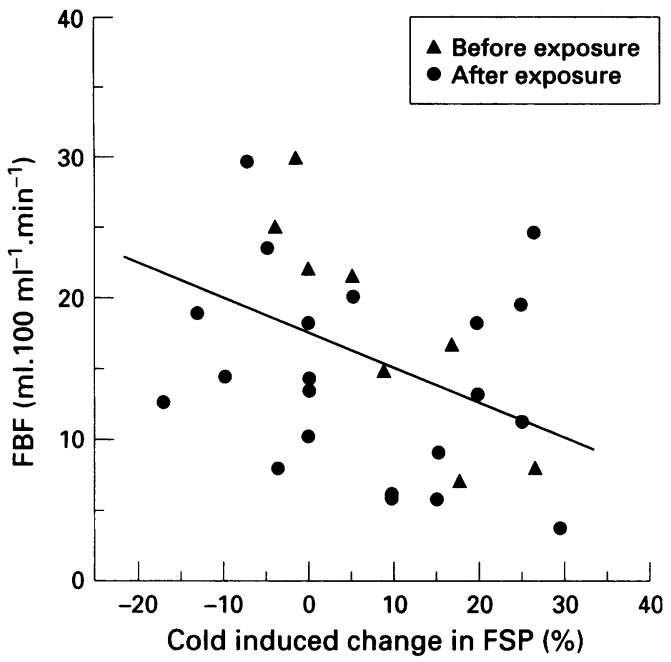

Figure 5 Regression of finger blood flow (FBF) on the percentage change in finger systolic pressure from 30 to $10^{\circ} \mathrm{C}(\mathrm{FSP} \%)$ measured in the test finger before and after 30 minutes exposure to vibration: $F B F=17 \cdot 4-0 \cdot 25$ $(F S P \%) ; r=-0.42(P=0.019)$

each measurement interval during recovery $(P<0.001)$. Compared with before exposure, a reduction in $\mathrm{FBF}$ of $52 \%$ in the control left finger and of $44 \%$ in the test right finger was found at 90 minutes after the end of vibration exposure. The percentage reduction in FBF over the 90 minutes relative to the FBF before vibration was inversely related to the digital vasodilation that occurred immediately after the end of vibration exposure (fig 3). According to the results of repeated measures ANCOVA, vibration induced a significant reduction in FST in both fingers, even though the percentage change from the baseline values was smaller than that found for FBF (table 4). The general pattern of haemodynamic changes showed that differences in the vascular response to vibration between subjects were less pronounced than those seen with exposure to static load only. The FBF was found to be highly correlated with FST in both the vibrated and non-vibrated fingers $(P<0.001)$. Analysis of data transformation and residuals showed that logarithmic transformation of blood flow values was the most appropriate for modelling the relation between FBF and FST (fig 4). No significant variations in cold induced change in FSP\% after vibration exposure were found for either finger (table 5). Nevertheless, in the vibrated right hand the decrease in FBF was significantly related to cold induced vasoconstriction in the

Table 5 Median values (lower and upper quartiles) for the change in finger systolic pressure from 30 to $10^{\circ} \mathrm{C}(\%)$, adjusted for changes in arm systolic pressure, measured in eight healthy men before and after 30 minutes of exposure to static load (contact force $10 \mathrm{~N}$ ) and vibration (acceleration $87.5 \mathrm{~ms}^{-2} \mathrm{rms}$ at $125 \mathrm{~Hz}$ )

\begin{tabular}{lccccc}
\hline & \multicolumn{2}{l}{ Static load } & & \multicolumn{2}{l}{ Vibration exposure } \\
\cline { 2 - 3 } \cline { 5 - 6 } Period & Exposed finger & Non-exposed finger & & Exposed finger & Non-exposed finger \\
\hline Before exposure & $-0.3(-7 \cdot 5-18 \cdot 7)$ & $5 \cdot 6(-0 \cdot 2-17 \cdot 3)$ & & $8 \cdot 0(0-17 \cdot 2)$ & $-0 \cdot 6(-10 \cdot 3-8 \cdot 9)$ \\
Recovery (min): & $7 \cdot 7(-1 \cdot 5-19 \cdot 0)$ & $5 \cdot 5(-4 \cdot 5-18 \cdot 2)$ & & $7 \cdot 0(-3 \cdot 2-22 \cdot 3)$ & $6 \cdot 8(0-10 \cdot 2)$ \\
$\quad$ R 15 & $11 \cdot 0(-2 \cdot 3-24 \cdot 0)$ & $7 \cdot 5(-2 \cdot 0-31 \cdot 3)$ & & $7 \cdot 0(-2 \cdot 1-14 \cdot 0)$ & $6 \cdot 4(0 \cdot 2-13 \cdot 7)$ \\
R 30 & $7 \cdot 8(1 \cdot 9-22 \cdot 4)$ & $3 \cdot 5(-0.9-15 \cdot 8)$ & & $17 \cdot 3(-2 \cdot 7-26 \cdot 1)$ & $7 \cdot 0(-0 \cdot 3-17 \cdot 2)$ \\
R 60 & 0.245 & 0.328 & & 0.284 & $0 \cdot 106$ \\
ANCOVA & P value) & & & & \\
\hline
\end{tabular}

$P$ values are adjusted by age, finger volume, and room temperature. 
digital vessels (fig 5). Such a relation was not found in the non-vibrated left hand.

\section{Discussion}

This study showed that both the variability of the response and the effect of independent variables other than vibration should be carefully taken into account to interpret the reaction of digital circulation to acute exposure to hand transmitted vibration. Variability between subjects was particularly evident for finger blood flow and, to a lesser extent, for finger skin temperature. The physiological variations in finger haemodynamics were due, at least partially, to the influence of individual characteristics and environmental conditions. These findings are consistent with reports from other investigators who found a great physiological variability of blood flow and skin temperature in normal fingers with different stressors. ${ }^{12} 1527$ In his pioneering work, Burton found wide rhythmic fluctuations in the finger blood flow of seven normal subjects in comfortable environmental conditions such that successive determinations of flow, made only a few seconds apart, differed by as much as $50 \%$ from their average value.$^{28}$ It is likely that such rhythmic fluctuations of vasomotor origin are linked to the function of fingers as radiators of body heat to regulate internal temperature. Investigators have often used finger skin temperature as an indirect indicator of digital blood flow. ${ }^{27} 2931$ Nevertheless, in this study the relation of finger skin temperature with finger blood flow was far from being simply linear. It is well known that skin temperature depends not only on the rate of subcutaneous blood flow, but also on the rate of evaporation of sweat and on several environmental variables such as air temperature, mean radiant temperature, ventilation, and humidity. Under physical stress finger skin temperature is unable to follow rapid changes in digital blood flow, even in acceptable thermal environments. ${ }^{15}$ Therefore it was considered that blood flow, compared with skin temperature, is likely to be a more reliable measure of the transitory haemodynamic changes that occur in the human finger exposed to acute vibration.

As well as environmental conditions, physiological investigations have also shown that the response of the human finger to various stressors is dependent on age, sex, and body constitution. ${ }^{32} 33$ These findings indicate that several confounding factors should be controlled to explain the changes in digital circulatory function induced by the exposure of interest.

The results of this study indicate that after adjustment for potential confounders, acute vibration can induce significant changes in the blood flow and skin temperature of both the ipsilateral exposed and the contralateral nonexposed finger in normal men. In contrast, alterations in the digital circulation were not found in a control condition represented by exposure to static load without vibration. In the contralateral finger the vibration produced vasoconstriction, whereas in the ipsilateral finger there was an initial vasodilation followed by vasoconstriction after the end of vibration. In the exposed finger the vasodilation found immediately after vibration diminished the extent of vasoconstriction compared with the non-exposed finger. Therefore, the present results seem to suggest that vibration produces local vasodilation and triggers a reflex vasoconstriction that can be recorded in the ipsilateral and the contralateral finger. $A$ further study to monitor the change of finger blood flow during exposure to vibration may be required to determine the degree to which duration of exposure to vibration influences the degree of vasoconstriction. Physiological experiments on isolated preparations of arteries and veins have shown that vibration can depress the contractile force of smooth muscle. ${ }^{3435}$ Azuma et al also showed that the responsiveness to noradrenaline of excised femoral arteries of dogs and rats was considerably reduced during vibration stimulation. ${ }^{36}$ These findings were confirmed by in vivo experiments that reported a decrease in total vascular resistance in vibrated intact limbs of dogs. ${ }^{37} 39$ Similar after effects of vibration have also been found in human skin arterioles. ${ }^{40} \mathrm{An}$ explanation of the vibration induced relaxation in vascular smooth muscle has been offered by Ljung and Sivertsson who postulated that vibration exerts a direct inhibition of the contractile process by affecting the interaction between actin and myosin filaments. ${ }^{34}$

In this study, blood flow and skin temperature in the vibrated and non-vibrated fingers significantly decreased 60-90 minutes after vibration ended. The extent of digital vasoconstriction was inversely related to the dilatation found immediately after the end of vibration exposure. It has been hypothesised that vibration can reduce digital blood flow through a sympathetic reflex mechanism that provokes vasoconstriction in both the ipsilateral and the contralateral finger. ${ }^{8}$ This hypothesis has been confirmed by various researchers who investigated the vascular response to acute vibration in the fingers of workers exposed to vibration such as chain saw operators and other groups of patients with VWF. ${ }^{11241}$ Hyvärinen et al found that vibration of $125 \mathrm{~Hz}$ was the most effective vibration frequency in triggering digital vasospasm in lumberjacks affected with VWF. ${ }^{8}$ Welsh reported that digital blood flow was reduced maximally by a frequency of 120 $\mathrm{Hz}$ in male volunteers. ${ }^{9}$ There is neurophysiological evidence that vibration of this frequency can stimulate skin mechanoreceptors such as the Pacinian corpuscles, which may represent the afferent branch of the sympathetic reflex arch elicited by vibration. ${ }^{842}$

A vasomotor effect in areas beyond those excited by vibration has been reported in several experimental studies with shorter exposures (one to five minutes) than those of the present investigation. Sakakibara et al found both an increase in the skin sympathetic activity from the right tibial nerve and a decrease in the amplitude of the plethysmogram from a toe of the right foot when vibration of 100 $\mathrm{m} \cdot \mathrm{s}^{-2}$ at $60 \mathrm{~Hz}$ was applied to the left hand for one minute. ${ }^{43}$ Reduction in finger blood flow 
or finger skin temperature on the side contralateral to the site of vibration stimulation has also been reported by Nasu who used thermography, ${ }^{44}$ by Färkillä and Pyykkö who used photoplethysmography, ${ }^{45}$ and by Furuta et al who used laser Doppler blood flowmetry. ${ }^{10}$

In 12 normal subjects exposed for $30 \mathrm{~min}$ utes to unilateral vibration of $16 \mathrm{~m} \cdot \mathrm{s}^{-2}$ at 31.5 $\mathrm{Hz}$, Olsen found a stronger vasoconstrictor response to cold than that found in this study. ${ }^{14}$ This may be due to differences in cold provocation tests that consisted of both local and body cooling in the Danish study. In the present investigation, a significant relation between the decrease in blood flow in the index finger and the increase in the vasoconstrictor response to cold in the ring finger was found only in the vibrated hand. The response of arteries and veins to physical and humoral stimulation after vibration exposure has been explored by means of several experimental procedures. With digital nerve blockade, it has been shown that in human fingers vibration can induce hyperresponsiveness to cold in the digital arteries through an exaggerated sympathetic reflex mechanism. ${ }^{12}$ Azuma et al found an increased arterial vasoconstrictor response to noradrenaline in the hindlimb of anaesthetised dogs one hour after the end of vibratory stimulation. ${ }^{46}$ These authors hypothesised that VWF is a localised circulatory insufficiency due to vibration induced hyperresponsiveness of arterial smooth muscle to noradrenaline in the vibrated fingers. On the contrary, Lindblad et al did not find significant changes in the contractile response to electrical stimulation nor to noradrenaline in in vitro preparations of innervated canine arteries exposed to vibration for three to 16 hours. ${ }^{47}$ Hence, the role of possible local after effects of vibration in sensitising the vascular smooth muscle cells to cold or vasoactive substances is still unclear.

In summary, the results of this study, together with those of both in vivo and in vitro experiments, suggest a complex interaction between mechanical vibration and digital circulation. It seems that acute vibration can disturb the function of digital vessels through two different and opposite mechanisms. The vasodilation found in the vibrated finger immediately after vibration is probably due to a direct, local, relaxing effect of vibration on the smooth muscles of the vessel wall, whereas the reduction in blood flow recorded in both the vibrated and the non-vibrated fingers during recovery may reflect a vibration induced vasoconstrictor response through a central sympathetic reflex mechanism. The responsiveness to cold found only in the digital vessels of vibrated fingers may suggest a combined effect of local and central vasoconstrictor mechanisms elicited by acute vibration. A role for central sympathetic mechanisms seems to be well established in both normal subjects and patients with various forms of Raynaud's phenomenon, ${ }^{48}$ whereas the nature of local mechanisms has not yet been clarified. Both vibration induced endothelial injury and dysfunction of adrenergic receptors have been suggested by some investigators, ${ }^{6}{ }^{12}$ but further research is needed to increase the understanding of the local pathogenic mechanisms involved in the digital vasoconstriction caused by hand transmitted vibration. The conduction of a similar study among people who show signs and symptoms of VWF could contribute to improvement of the basic pathophysiological knowledge of the vascular disorders induced by hand transmitted vibration.

It has been suggested that the aetiology of VWF is multifactorial as the probability and severity of this vascular disorder is the result of the interrelation between several determinants both of exposure at the workplace (vibration characteristics, source of vibration, environmental conditions) and individual aspects (method of tool use, fitness, susceptibility). ${ }^{7}$ In the present investigation, the experimental conditions (magnitude, frequency, and duration of vibration) were chosen to simulate vibration exposure at workplaces excluding the influence of ergonomic factors such as hand grip or tool operating technique. Consistent with the results of previous studies, our findings suggest that acute vibration on its own can affect blood circulation in the normal finger. The epidemiological evidence of the reversibility of VWF in the early stages after the end of exposure suggests that initially the increase of the vascular tone in the digital circulation may be a transitory disorder. Long term exposure to harmful vibration combined with other factors - for example, grip force and cold-might cause repeated episodes of abnormal vasoconstriction in the finger leading to permanent changes in the vasculature and the irreversibility of symptoms in severe cases of VWF.

1 Olsen N. Centrally and locally mediated vasomotor activities in Raynaud's phenomenon. Scand $\mathcal{F}$ Work Environ Health 1987;13:309-12.

2 Takeuchi T, Futatsuka M, Imanishi H, Yamada S. Pathological changes observed in the finger biopsy of patients with vibration-induced white finger. Scand $f$ Work Environ Health 1986;12:280-3.

3 Ekenvall L, Lindblad LE, Bevegård S, Etzell BM. High vascular tone but no obliterative lesions in vibration vascular tone but no obliterative lesions
white fingers. $A m$ f Ind Med 1987;12:47-54.

4 Behrens VJ, Pelmear PL. Epidemiology of hand-arm vibration syndrome. In: Pelmear PL, Taylor W, Wasserman $\mathrm{DE}$, eds. Hand-arm vibration - a comprehensive guide for occupational health professionals. New York: Van Nostrand Reinhold, 1992:105-21.

5 Bovenzi M. Cardiovascular responses to autonomic stimulation in vibration-induced white finger. Eur $\mathcal{f} A p p l$ Physiol 1989;59:199-208.

6 Gemne G. Pathophysiology of white fingers in workers using hand-held vibrating tools. Nagoya $\mathcal{F}$ Med Sci 1994; 57(suppl):87-97.

7 Griffin MJ. Handbook

8 Hyvärinen J, Pyykkö I, Sundberg S. Vibration frequencies and amplitudes in the aetiology of traumatic vasospastic
and and amplitudes in the aetiolo
disease. Lancet 1973;i:791-4.

9 Welsh CL. The effect of vibration on digital blood flow. $\mathrm{Br}$ f Surg 1980;67:708-10.

10 Furuta M, Sakakibara H, Miyao M, Kondo T, Yamada S. Effect of vibration frequency on finger blood flow. Int Arch Occup Environ Health 1991;63:221-4.

11 Kent PJ, Williams G, Kester RC. Altered sensitivity of digital blood flow to acute vibration in patients with vasospastic disease. F Biomed Eng 1991;13:269-71.

12 Greenstein D, Kester D. Acute vibration-its effect on digital blood flow by central and local mechanisms. Proc Inst Mech Eng 1992;206:105-8.

13 Ishitake T, Nakagawa K, Iwamoto J, Matoba $T$. tion in the conscious in skin microcirculation by vibraInternational Conference on Hand-Arm Vibration. Sankt 
Augustin: Hauptverband-der-gewerblichen-Berufsgenossenschaften 1992:125-34.

14 Olsen N. Vibration after effects on vasoconstrictor response to cold in the normal finger. Eur F Appl Physiol 1993; 66:246-8.

15 Greenfield ADM. The circulation through the skin. In: Hamilton WF, ed. Handbook of physiology, section 2 (circulation, vol II). Washington, DC: American Physiological Society, 1963:1325-51.

16 Roddie IC. Circulation to skin and adipose tissue. In: Shepherd JT, Abboud FM, eds. Handbook of physiology, section 2 (the cardiovascular system, vol III). Bethesda: American Physiological Society, 1983:285-317.

17 Griffin MJ. Foundations of hand-transmitted vibration standards. Nagoya $\mathcal{F}$ Med Sci 1994;57(suppl):147-64.

18 British Standards Institution. Guide to safety aspects of experiments in which people are exposed to mechanical vibration and shock. London: BSI, 1989:7085.

19 Garrett JW. Anthropometry of the hands of male airforce flight personnel. Aerospace Medical Research force flight personnel. Aerospace

20 Greenfield ADM, Whitney RJ, Mowbray JF. Methods for the investigation of peripheral blood flow. Br Med Bull 1963;19:101-9.

21 Nielsen SL, Lassen NA. Measurement of digital blood pressure after local cooling. $\mathcal{F}$ Appl Physiol 1977;43. 907-10.

22 International Organization for Standardization. Mechanical vibration-guidelines for the measurement and the assessment of human exposure to hand-transmitted vibration. Geneva: ISO, 1986:5349.

23 British Standards Institution. Measurement and evaluation of human exposure to vibration transmitted to the hand. human exposure to vibratio

24 Crowder MJ, Hand DJ. Analysis of repeated measures. London: Chapman and Hall, 1990.

25 Anderson TW. An introduction to multivariate statistical analysis. New York: John Wiley, 1958

26 Greenhouse SW, Geisser S. On methods in the analysis of profile data. Psychometrika 1959;24:95-111.

27 Cleophas TJM, Fennis JFN, van't Laar A. Finger temperature after finger-cooling test: influence of air temperature and smoking. Fournal of Applied Physiology: Respiratory, Environmental and Exercise Physiology 1982;52:1167-71.

28 Burton AC. The range and variability of the blood flow in the human fingers and the vasomotor regulation of body the human fingers and the vasomotor regula

29 Kondo T, Sakakibara H, Miyao M, Akamatsu Y, Yamada S, Nakagawa T, et al. Effect of exposure to hand-transmitted vibration on digital skin temperature change. Ind Health 1987;25:41-53.

30 Scheffer $M$, Dupuis $H$. Effects of combined hand-arm vibration and cold on skin temperature. Int Arch Occup Environ Health 1989;61:375-8.

31 Sandover J, Louw J. Acute effects of grip force and vibration on finger temperature. In: Proceedings of the 6th International Conference on Hand-Arm Vibration. Sankt Augustin: Hauptverband-der-gewerblichen-BerufsgenosAugustin: Hauptverband-d
senschaften 1992:211-8.
32 Spurr GB, Hutt BK, Horvath SM. The effects of age on finger temperature responses to local cooling. Am Heart $\mathcal{f}$ 1955;50:551-5.

33 Wagner JA, Horvath SM. Influences of age and gender on human thermoregulatory responses to cold exposures. $f$ Appl Physiol 1985;58:180-6.

34 Ljung B, Sivertsson R. Vibration-induced inhibition of vascular smooth muscle contraction. Blood Vessels 1975; 12:38-52.

35 Lindblad LE, Lorenz RR, Sherpherd JT, Vanhoutte PM. Effects of vibration on a canine cutaneous artery. $A m \mathcal{f}$ Physiol 1986;250:H519-23.

36 Azuma T, Ohhashi T, Sakaguchi K. Vibration-induced hyperresponsiveness of arterial smooth muscle to adrenaline with special reference to Raynaud's phenomenon in vibration disease. Cardiovasc Res 1978;12:758-64.

37 Liedtke AJ, Schmid PG. Effect of vibration on total vascular resistance in the forelimb of the dog. $\mathcal{F}$ Appl Physiol resistance in the

38 Bhattacharya A Knapp CF, McCutcheon EP, Edwards RG. Parameters for assessing vibration-induced cardioRG. Parameters for assessing vibration-induced cardio-
vascular responses in awake dogs. $\mathcal{F}$ Appl Physiol 1977; 42:682-9.

39 Ohhashi T, Ikomi F. Vibration-induced increase of the lymph flow rate in canine hindlimb with special reference to Raynaud's phenomenon in vibration disease. In: Okada A, Taylor W, Dupuis H, eds. Hand-arm vibration. Kanazawa: Kyoei Press, 1990:19-22.

40 Olsen N, Petring OU, Rossing N. Transitory postural vasomotor dysfunction in the finger after short term hand vibration. Br f Ind Med 1989;46:575-81.

41 McKenna KM, Blann AD, Allen JA. Vascular responses in chain saw operators. Occup Environ Med 1994;51: chain saw-70.

42 Lunström R. Responses of mechanoreceptive afferent units in the glabrous skin of the human hand to vibration Scand $\mathcal{F}$ Work Environ Health 1986;12:413-6.

43 Sakakibara H, Iwase S, Mano T, Watanabe T, Kobayash F, Furuta $M$, et al. Skin sympathetic activity in the tibia nerve triggered by vibration applied to the hand. Int Arch Occup Environ Health 1990;62:455-8.

44 Nasu $T$. Changes of the skin temperature caused by local vibratory stimulation in normals and patients with vibration syndrome. Yonago Acta Medica 1977;21:83-99.

45 Färkillä M, Pyykkö I. Blood flow in the contralateral hand during vibration and hand grip contractions of lumberiacks. Scand f Work Environ Health 1979;5: lumberjacks

46 Azuma T, Ohhashi T, Sakaguchi K. An approach to the pathogenesis of "white finger" induced by vibratory stimulation: acute but substained changes in vascular responsiveness of canine hindlimb to noradrenaline. Cardiovas Res 1980;14:725-30

47 Lindblad LE, Lorenz JT, Vanhoutte PM. Prolonged vibration of cutaneous arteries: absence of persisting after effects. Experientia 1984;40:1372-3.

48 Olsen N, Hansen SW. Vasomotor functions of skin microcirculation in vasospastic Raynaud's phenomena. Acta Physiol Scand 1992;143 (suppl 603):101-7.

\section{Rejected manuscripts}

From February 1994, authors whose submitted articles are rejected will be advised of the decision and one copy of the article, together with any reviewers' comments, will be returned to them. The fournal will destroy remaining copies of the article but correspondence and reviewers' comments will be kept. 